\title{
Qualitative data for examining fixed and incremental concepts of language learning: A search for the stories behind students' motivation
}

\author{
Laura V. Fielden Burns* and Mercedes Rico García \\ Department of English Philology, Faculty of Education, University of Extremadura, Badajoz, Spain \\ Department of English Philology, Faculty of Education, University of Extremadura, C.U. Mérida, Mérida, Spain
}

\begin{tabular}{|c|c|}
\hline \multicolumn{2}{|c|}{$\begin{array}{l}\text { learning, qualitative interviews can offer further depth and insight on these beliefs, by shedding } \\
\text { light on the detail of the experiences behind student perceptions. This is important to } \\
\text { understanding student motivation in the language classroom, since beliefs form one of the } \\
\text { important pillars behind motivation and language learning goals. The present study analyzed } \\
\text { beliefs for } 8 \text { students in English for Hospitality vocational courses ( } 2 \text { male and } 6 \text { female from } 25 \\
\text { to } 43 \text { years of age) in one-to-one, narrative interviews, looking both to the content of what } \\
\text { students chose to share and the form in which they expressed themselves. This population is } \\
\text { particularly interesting given that other studies in vocational studies indicate a lack of study } \\
\text { persistence due to problems in motivation. Utilizing this qualitative, open-ended approach } \\
\text { allowed the authors to more specifically examine how students conceive language learning } \\
\text { when understood as a story of their experience with languages. The rich descriptions that } \\
\text { emerge from this methodology have import for future curriculum planning, as they describe in } \\
\text { more detail students' tendencies to categorize language learning as something passive or active, } \\
\text { as an object or as a process, which should be taken into account in course planning to optimize } \\
\text { study persistence. }\end{array}$} \\
\hline \multicolumn{2}{|c|}{$\begin{array}{l}\text { Keywords: EFL/ESP; student beliefs; qualitative data; narrative interviews; vocational } \\
\text { programs }\end{array}$} \\
\hline $\begin{array}{l}\text { First Received: } \\
1 \text { April } 2017\end{array}$ & $\begin{array}{l}\text { Accepted: } \\
9 \text { March } 2018\end{array}$ \\
\hline $\begin{array}{l}\text { Final Proof Received: } \\
29 \text { May } 2018\end{array}$ & \\
\hline $\begin{array}{l}\text { Tow to cite (in APA style): } \\
\text { 3urns, L. V. F., \& García, M. R. (2018). C }\end{array}$ & $\begin{array}{l}\text { mining fixed and incremental } \\
\text { behind students' motivation. } \\
\text { loi: } 10.17509 / \text { ijal.v8i1.11471 }\end{array}$ \\
\hline
\end{tabular}

\section{INTRODUCTION}

Students' beliefs about language learning are important to their overall motivation and language learning goals (Barcelos \& Kalaja, 2011). Although quantitative selfreport questionnaires can investigate beliefs (Horwitz, 1999) on areas like the nature of language learning or language learning aptitude, among others, qualitative interviews can offer further depth and insight on these beliefs, helping shed light on the personal experiences behind student perceptions. For this reason, we analyzed beliefs of students in English for Hospitality vocational courses in one-to-one, narrative interviews, looking both to the content of what students chose to share (the what), and the form of the sharing (the how), which are necessarily intertwined (Miller \& Dingwall, 1997). Utilizing this qualitative, open-ended approach allowed us to more specifically understand how students conceive language learning when understood as a story of their experience with languages, in descriptions where students determine how to express themselves.

\footnotetext{
* Corresponding author

Email: 1vfielden@unex.es
} 
Such texture is uniquely available in quantitative data that looks at students' experiences holistically. Understanding this detail adds to the current literature on student beliefs by offering a more in-depth perspective on them in a student population of particular vulnerability. Vocational programs have a high level of student drop-out in Spain (Ministerio de Educación, Cultura y Deporte, 2016; ReferNet Spain, 2013; ComasForgas et al., 2015), and studies (Comas-Forgas, et al., 2015; European Commission, 2013; Mulder, Kahmann, Laubenbacher, \& Messmann, 2006) have noted that motivation may be key to this phenomena, though they have not specified details. Since motivation is related to student beliefs, gaining insight into these through students' descriptions of language learning as a story of their own telling may help us better comprehend their relationship to study persistence.

To address this objective, we asked students about their general language learning experiences in semistructured, narrative interviews which allowed them to determine the pace, direction and language for conceptualizing their beliefs and experiences. In particular, we looked for descriptions pointing to beliefs concerning the malleability (as versus innate quality) of language aptitude, and how much one can change her or his aptitude and progress towards language mastery through effort, so that we might better understand the degree to which students feel in control of their language learning process. This paper discusses such beliefs for students in English for Hospitality courses, noting the similarities and differences of the descriptions of the interviewed students to address both common and individual themes. The rich descriptions that emerge from this methodology have import for future curriculum planning, as they describe in more detail students' tendencies to categorize language learning as something passive or active, which should be taken into account in course planning to optimize study persistence and reduce student drop-out in vocational programs.

\section{Language learning conceptualizations}

The growing research behind language learning beliefs has created a desire to understand what lies behind students' perceptions, in particular how these affect their motivation and drive their behavior, including their learning strategies and willingness to continue on a determined path of study (Brown, 2009). Both of these factors, motivation and behavior, ultimately affect their achievement in language mastery. Some studies (Fielden \& Rico, 2017) have looked at student beliefs quantitatively, but little research has explored in depth the detail behind such itemized beliefs, in particular beliefs concerning how incremental or fixed they consider language learning and aptitude to be.

\section{Fixed and incremental mindsets}

Important to the study at hand was the fixed/growth mindset framework (Dweck, 2000) in social psychology and motivational research, which has revealed in numerous investigations that students of all ages who see certain basic qualities (intelligence, cultural characteristics, ethics) as more fixed and static tend to display more negative responses in the classroom than those that see these as more incremental or malleable. Such negative responses have been a tendency to avoid risk and choose performance goals over learning goals, lower persistence in the face of challenges, and higher levels of anxiety in class (Dweck, 2000). This framework is pertinent to the language classroom as well, in particular when applied to students' beliefs concerning language learning acquisition and the concept of language learning aptitude. Yet we know little about how students describe language learning aptitude and no study has examined such beliefs qualitatively while looking for incremental or fixed descriptions of the language learning process. For this reason, we chose to interview students on their beliefs, beginning with their particular learning experience as a personal narrative.

\section{Narrative approach and personal meaning creation}

In relating their language learning experiences in a narrative interview setting, respondents are offering verbal data, which are increasingly used in research, particularly in the areas of sentiment expression, attitudes and beliefs (Foddy, 1993). The narrative approach to verbal data seeks to look at spontaneous language as a way to best approximate interviewees' personal representations of lived experiences. It encourages the informant to discuss important events in her or his life and the social context around these. First developed by Schultz in the 1970's, narrative interviews may reveal different attitudes toward life experiences (Anderson \& Kirkpatrick, 2016). Narrative interviews (Muylaert, Sarrubi, Gallo, Neto, \& Reis, 2014) treat the interview as a story that is told by the respondent, where she or he selects the elements to recount, and the order in which to tell them. An advantage of this approach is that the respondent has an important role in constructing meaning in the interview (Gillham, 2005) as it allows respondents to take ownership of the interview. The main questions of these interviews follow an unstructured or semi-structured approach, where the catchment area is as wide as possible, avoiding singleword responses and allowing the respondent to guide the interview. An in-depth perspective is preferred over a superficial one, and a less distanced interview posture (Fontana, 2007) is expected. The main point is to engage in a human-to-human interaction with the respondent to try to understand her or his view (ibid.), since understanding is in fact is the point of qualitative research (Minayo, 2012).

In narrative interviews, we consider that our memory is selective, we remember what 'we can' and some events are deliberately or unconsciously forgotten. In this perspective, the important thing is that the person recorded in his/her history, what he/she experienced, what is real to her/him and not the facts themselves (past 
versus history) (Muylaert, Sarrubi, Gallo, Neto, \& Reis, 2014, p.186).

\section{Interviewer and respondent interaction}

Narrative interviews also implicate the interviewer in a social sense, so that meaning is negotiated as informants construct their narratives. Foddy's four tenets of symbolic interactionism are pertinent to this negotiation, where, 1) given that any topic is multidimensional, any topic can be defined in one or various dimensions; 2) items can occur on different levels of generality, in that they can be orientated individualistically or pluralistically, around personal or normative terms, 3) responses can be made on a number of theoretical levels, discussing $\mathrm{X}$ or discussing discussing $\mathrm{X}$, and 4) utterances always come within their own frame of reference that is descriptive, explanatory or evaluative (Foddy, 1993, p. 22). The concept of "practical production" is also important in terms of the researcher's role in the interview (Fontana, 2007 p. 41) which says that meaning is accomplished at the intersection of interaction of the interviewer and the respondent. Thus, a less distanced approach is essential for narrative interviews in general (Muylaert, Sarrubi, Gallo, Neto, \& Reis, 2014). In the case at hand, the interviewer was the former teacher for the English for Hospitality courses. In a structured interview, this could be considered detrimental to structured response choices, but here it is an essential part of the interview itself. It is on the basis of a past teacher-student relationship that an inquiry into their personal history of language learning makes sense. Again, generally speaking, this is in line with the need to establish rapport in less structured interviews and narrative approaches, so that the respondent feels comfortable enough to share her or his experiences.

Recent literature in the use of interviews reveals important theoretical underpinnings. One is that in terms of interview analysis, seeing the interview as a whole narrative does not imply it must be coherent or uniform, since narratives and narrativity "move between cultural scripts ('canonicity') and totally idiosyncratic babble" (Hyvärinen, 2007, p. 456). We agree with Hyvärinen in his summary of narrative analysis methods in that narratives are mixed medium which combine elements of the past experiences as well as future expectations, "rather than just piecing together action sequences" (ibid, p. 456). He notes that modern narrative theories examine narratives with more sensitivity to recounting incomplete stories which may allow for mental states (observation, feelings cognitions) (ibid, p. 457) so that narrators account for past experiences while they also position themselves within "networks of social and cultural expectations" (ibid). This is a more interdisciplinary analysis of narratives than seen in the past.

Relatedly, Choo (2014) differentiates between using interviews as a data collection tool or as a social practice, and emphasizes that, because of the social quality of interviews, all of the interview context (every interviewer-respondent interaction) should be rendered and studied in analysis. This consideration is valid, however, the scope of this paper, being broad to include the interview data from 8 different individuals and 8 hours of recordings does not permit us, for now, to delve into an analysis of the sort Choo proposes, though this may also be undertaken at a later time for individual students.

\section{Previous Studies}

Early studies on student beliefs about the language learning process began mostly with quantitative tools developed by Horwitz in the 1980's, specifically her Beliefs about Language Learning Inventory (BALLI), which has been shown to be an adequate tool for examining beliefs across different languages and cultures (Nikitina \& Furuoka, 2006). This widely-used self-report questionnaire looks at student beliefs about foreign language aptitude, the difficulty of language learning, the nature of language learning, learning and communication strategies, and motivation and expectations. In the plethora of studies based on the BALLI, the majority of those queried agreed that an aptitude for language exists, a belief that is present across many cultures for students (Horwitz, 1999) where the majority of queried respondents did not feel they personally had foreign language aptitude.

In terms of qualitative research on students' beliefs using interviews, Szőcs' study (2017) employs interviews for instructors to understand their interpretations of concepts like learner autonomy in language learning, for example. Cui (2014), in 6 semistructured interviews of Chinese students in North America found that the role of culture was key to developing learners' beliefs on foreign language learning strategies (Cui, 2014). Finally, Barcelos (2000) looked at four ESL Brazilian students' and their three instructors' beliefs in interviews. The study's interesting results indicate the importance of teachers' and peers' influence on learner's beliefs as well as a strong relationship between students' beliefs and their personal identities, and finally, how beliefs about the "ideal" way to learn a language differentiate students' individual beliefs (p. 322). This last conclusion relates to the present study in that an ideal way to study represents a possibly fixed concept of the language learning process that can affect student motivation.

\section{Research objectives}

Our objective in this study was to determine if fixed and incremental characteristics (Dweck, 2000) of the language learning process were present in students' descriptions of their experiences. We examined these through the content and form of their descriptions, the what and how of narrative interviews, looking both at common themes for all interviewed students as well as individualized themes for particular students. We looked then at the what and how of students' narratives in the following format:

1. Common themes (all students mention) 
2. Individual themes (some students mention, in varying ways)
a. Fixed descriptions
b. Incremental descriptions

In this case, fixed descriptions, for example, would characterize language acquisition as static, less able to be changed or controlled, as something had, and incremental would characterize it as progressive and individualized, where one does have control and can effect change. A student might choose to discuss teaching materials (what) as influential in her or his experience, and characterize these as incoherent and impossible to understand (how), using such formulations as categorical adjective lists alongside generalizations ("It's impossible". "No one gets it") to give the impression that he or she is not in control of the learning process because of the materials, which cannot be changed and whose difficulty is ubiquitous for all students using them. Such characterizations in the student narratives at these two levels (content in the what, form in the how) would point to the importance of fixed and malleable perceptions in beliefs about language learning in terms of the control students feel they exercise over their learning. Finally, comparing these descriptions for all the interviewed students allows us to determine what themes might be reoccurring for language students in these courses, as well as what might be more particular and local as seen in some students but not in others.

\section{METHOD \\ Narrative interviews: a methodological approach}

As previously discussed, there is a gap in student belief research in terms of better understanding how beliefs about the fixed or incremental nature of language learning and motivation intersect for students' continued study in language courses, particularly in vocational programs where a high level of drop-out is observed. Verbal data, increasingly important in research, offer a new vision onto this area with the potential to reveal important details. In particular, narrative interviews are an important methodological tool for investigating this verbal data, as they allow students to guide the interview and recount their experiences with language learning on their own terms and in their own language. This language in particular can reveal more about their beliefs than is possible to glean from quantitative studies only, offering a triangulation of data for this area.

\section{Interviews: Pre-interview}

Since interviewer and respondent engage in a questionanswer communication for which participants search for communication clues, there were a number of important bases to establish. To begin with, when respondents were asked to do the interview they were given information about its purpose in writing beforehand, so that they knew what it was for, and being told that they would be asked about their language learning experiences. This way, they could think about what they might want to share. Gillham (2005) indicates that this is a good practice for less structured interviews that seek general understanding of respondents' experiences. Respondents must be clear about the topic to be discussed.

\section{Interview structure}

Even in narrative interviews where respondents are meant to carry the conversation forward as they wish, some design is necessary for initiating, continuing, and concluding the conversation. Gillham's suggestions for interview structuring were heeded, including a transparent entry phase, possible prompts, and a summing-up closure phase. The first question of the interview initiated students' narratives, and was an invitation to recount their experiences. We told students, in their native, Spanish, tongue: Tell me about your experiences with languages, starting wherever and however you like. This question and one about aptitude: Do you think language learning aptitude exists ("habilidad con los idiomas") were the only two questions asked in all the interviews. The rest of the interview prompts or questions were related to language learning but followed students' leads as much as possible and so varied from one interview to the next, and many questions were mere inquiries to expand upon or clarify students' statements, or simply to move the interview forward by using normal conversational responses. For moving the interview along to other related topics, Gillham (2005) suggested process model was followed for prompts: listing questions that were important to the literature given the findings there and then identifying topics out of these in terms of: redundancy, relatedness and sequence. Later these were reduced by combining phrases that seemed to ask the same thing and weeding out questions that seemed redundant. In terms of format an attempt was made to ensure that the questions were "sayable", that they sounded natural and had clarity, that they did not carry a lot of verbal weight, were as short as possible and finally, that no compound questions were asked, as Gillham (2005) indicates. Questions were first written in English, and once essential content was established, translated to Spanish and given to a native Spanish speaker for feedback and alterations.

\section{Interview transcript analysis methods}

For the interview transcript analysis, we chose Miller and Dingwall's (1997) methodology for narrative interviews: the story, the content, or what respondents chose to tell and the discourse, of form, the how of this telling. In this sense, what is the sort of content the respondent chooses to share: does she only talk about experiences with teachers, or wholly those with other student peers, or does she focus on materials, or misunderstandings in spoken exercises? The content offered is representative of what is considered important for the respondent at that given time, in that given 
context). On the other hand, the how of the interview, when pertinent, focuses on the language used to describe the content. Here different perspectives are possible, such as examining lexical choice itself, or repetition of lexical items (indicating emphasis and importance), grammatical structures such as the use of active or passive constructions (which approximate or distance the speaker from a topic), hedging, generalizations, etc.

This can be done while examining the interview narrative as a whole through "analytical bracketing" as described by Fontana (2007), where multiple levels of the interview can be analyzed as separate but related segments, where we can analyze the interview in its totality and diversity as a collaborative even as product and process are "mutually constituted" (ibid, p. 41). In this sense, as noted earlier, seeing the interview as a whole narrative does not imply it must be coherent or uniform, since narratives are mixed medium where narrators account for past experiences while positioning themselves within social and cultural networks of expectations (Hyvärinen, 2007). This is a more interdisciplinary analysis of narratives than in the past (p. 457).

In terms of the analysis, it was important to see each student on her or his own terms first, before trying to draw any commonalities. First, local, dominant themes and the individual characteristics that emerged from the open-ended narrative responses were separated and indexed. As mentioned above, this analysis was done in two ways: by looking at the content that each individual chose to share as well as the specifics of how that content was discussed in terms of word choice, repetitions, patterned grammatical structures (more or less passive constructions, hedging), etc. Lastly, the indexed responses were examined to check for commonalities in general, as well as commonalties that were relevant to the focus areas: language aptitude or fixed or incremental qualities associated with language learning.

In order to do this analysis, basic coding techniques were used. Specifically, a color-code system was developed to mark specific sections of each transcript, in terms of reoccurring or interesting comments on aptitude or incremental/fixed qualities. For example, any student comment that referenced aptitude directly or indirectly was marked in green, etc. We codified each transcript accordingly, searching for both for local themes that seemed relevant to the individual, as well as global ones that were visible in the group of 8 interviewees.

\section{Chronology and timing}

Interviews were carried out after the course had finished and all final grades had been assigned, so that students would feel no undue pressure to participate or comment in any particular way. These interviews took place within 1-2 months after the courses ended. They lasted about an hour each, and were recorded.

\section{Participants}

The participants were adults $(\mathrm{N}=8)$ taking professional certification modules in a public hospitality school in Extremadura, Spain. The courses were two English for Restaurant Service (A1-A2 level) courses (90 hours), as well as English for Tourism (A2 level, 120 hours total) which makes them English for Occupational Purposes or English for Specific Purposes students in vocational programs. The students took part in the larger study voluntarily and were made up of a diverse range of ages, the youngest being 25 and the oldest being 43 . There were six women and 2 men interviewees, all of them had completed high school and four of them were unemployed at the time. All except one had completed some university studies. Seven of them came from the English for Tourism (A2) course, and 1 came from the English for Restaurant Service course (A1-A2).

\section{RESULTS ${ }^{1}$}

Our objective in this study was to determine if in the what and how of narrative interviews fixed and incremental characteristics (Dweck, 2000) of the language learning process could be heard in students' descriptions of their experiences commonly, for all of the students (common theme), or at the individual level (individual theme).

\section{Common themes}

Age. In both groups, students mentioned age as a factor to be taken into consideration in language study, in general referring to the idea that the earlier one begins language study the better one learns. In general, this seemed to be understood as a static concept one could not control or change and which definitively affected the pace and effectiveness of study. In two cases this was a bit more incremental, in that the focus on age was as a condition for which adapted learning or motivational strategies should be taken into consideration, in Student D and Student B.

Spanish educational system. In all the interviews, there were general comments made by students about the Spanish educational system, and often about what were perceived as its deficiencies. Some students discussed teachers with a dearth of preparation, both pedagogically in terms of teaching materials or methodology, as well as in their knowledge of the L2 itself, such as Students H and F. Some students, such as Student C and Student B, focused on the change in trends generationally where English is now an accepted part of the school curriculum and there is a general social expectation that one should learn it over other languages.

General need to know English. In general, one heard about a perceived obligation to learn English from the interviewed students, sometimes more or less

${ }^{1}$ Original interview quotes were in Spanish, which were translated to English by a team of native Spanish and English speakers. 
positive, though some applications were more personal than others. A couple of students mentioned just learning English for pleasure, such as Student B, however most demonstrated a rather instrumental motivation, feeling that English was good for future work options or travel. Some comments were more of a fixed nature; Student F lamented the difficulties the Spanish had in particular as compared to other nationalities (understanding this as innate), since they had to learn English and in her opinion, weren't capable of learning it; and Student $\mathrm{H}$ seemed to do this indirectly as well. Student C saw the need to learn English as a sort of imposed international obligation that he was shouldering good-naturedly. Student D talked about how the school system "saturated" one with English.

Difficulty or negative experiences in language learning. All students were able to recall some negative moments in their language learning process, and many of these experiences were orientated to language anxiety of some sort due to not understanding what was being said to them, either in class or abroad, such as with Student F and Students D and E.

Consistency. Students often mentioned the importance of "consistency" in language study. For some this seemed to mean academic study or discipline, an extension of schoolwork. For others, it seemed to mean investing time in English, such as when Students $\mathrm{A}$ and $\mathrm{F}$ talked about the need to be consistent and study every day. Student G said that consistency was one of the most important things for progression in language study, and her methods focused on this academically. Student B described routinely reviewing material 15 minutes before a class, or redoing her notes to make sure she understood them. Student A talked about consistency as time dedicated to studying, and lamented that she didn't have enough.

English aptitude. All students felt that aptitude for languages existed when asked about it, and no one indicated she or he had this particular aptitude. Student D was reticent to say that an aptitude existed, and instead called this a "predisposition" which she then went on to describe as having to do with having the habit or, no, of studying. She mentioned as an example other, older, students who had trouble in her online degree program because it had been years since they "picked up a book". In terms of language use when describing aptitude, students talked less about a gift or talent for languages, and more often about having "an ear" for them, which might be perceived as a rather static construct. Overall, aptitude seemed to be defined as a certain ability to learn English either more quickly or with more ease.

Desire to learn. All students indicated that they wanted to learn their L2, whether it be by worrying over not being able to write English or understand it, trying to find the best method to do so (as both Students A and $\mathrm{F}$ expressed), or working in great detail on color-coded grammar notes or vocabulary as a study strategy (Student G). In fact, all the students had specific, positive comments about struggles with learning languages that sounded more incremental, even when some of their comments were more fixed in other areas of the interview. For example, Student $G$ called the difficulty of German a "challenge" she enjoyed; Student E indicated she would like to "finally" learn English after many perceived failed attempts, and Student A commented that she wanted to see how far she could go with English and for that reason continued. Student $\mathrm{H}$ said he had set English proficiency as a goal for 2014, though he did so unrealistically, being that his level was around an A2.

\section{Individual themes: Fixed descriptors}

In this case, fixed characterizes language acquisition as static, less able to be changed or controlled, as something had, and incremental would characterize it as progressive and individual, where one does have control and can effect change. Again, characterizations like these in the student narratives at these two levels (content in the what, form in the how) would point to the importance of fixed and malleable perceptions in beliefs about language learning. At the individual level, students gave varying descriptions which referenced a more static, fixed concept of language aptitude, which are grouped here into descriptive areas.

Language aptitude: Error or think-free. Some students seemed to understand aptitude as not having to work at learning languages or think about what one says, or that one does not make mistakes, or that languages just come. Student F mentioned that some people don't have to "think" about what they are going to say. For Student A, some people could just pick a basic level of language up after a few days abroad. Student $\mathrm{H}$ mentioned that after a few months of study one should be conversational in English, or after watching enough TV (Student F and Student $\mathrm{H}$ ). Student $G$ talked about how an exceptional colleague could move between various languages without mixing them or thinking about them at all. Student G also acknowledged that some of those in her class whom she felt had aptitude also worked hard or were accustomed to taking language courses; but she then returned to a more static concept: some people just don't make errors. They do it perfectly.

Passive, fixed concepts in language acquisition. Another facet of students' individual descriptions as more fixed were associations with more passive descriptors for language learning; some described language acquisition as something like a container: language was possessed, had. Student A frequently used the word base, a "foundation" in language that is had, and lost or damaged, as she claimed in her traumatic experience with English. She spoke of her time in Portuguese class as a skill she now had "in the bag," something done and possessed. Student F talked about language communication almost as a mail slot, as "receiving information." She also saw language learning as a "switch" that was turned on within someone, or as a sudden shift in comprehension once enough saturation 
was reached. Finally, Student $\mathrm{H}$ discussed language aptitude and talent as something that some innately talented persons "wasted" and did not take advantage of, and which he clearly tied to rigid ideas of social and cultural boundaries, where some persons of inferior means wasted time and abilities. The how of these descriptions was a list of objects where language acquisition is equivalent to something that is possessed, or acted upon ("wasted" "in the bag", etc.).

Another component of this passive conceptualization was discussing language as the result of a rote skill (what). In some cases, they discussed memorization or repetition as a learning strategy, which is a sort of consumption of the language-as-an-entity: Learn English in 150 Essential Words, etc. Both Students A and F talked about memorization strategies, and Student $F$ talked about how she tried listening to English verbs in her sleep, though both admitted that these systems had not worked for them. Student A brought up in detail the importance of vocabulary, again referring to the need to have a base (foundation) and using this word repeatedly.

Hierarchical concepts: Correctness. Also interesting to fixed characteristics was that some of the students brought up the importance of correctness in a way that indicated there was an only one proper or best way to study, one way that "works". Some of these were focusing on correct pronunciation or not having an accent, having native teachers, and spelling. Students $F$ and A talked about pronunciation and the need for native teachers, and Student A specifically associated her difficulties to periods when she had non-native instructors. Students $A$ and $G$ also talked about the importance of correct spelling as indicative of language achievement. Students $\mathrm{H}$ and $\mathrm{F}$ seemed to be more focused on absorbing spoken English from a given environment and indicated that only English should be spoken in class.

Learning as sudden acquisition, not incremental. Though many of these students were able to see changes in their own language learning process, much of their focus was on the suddenness of such change, such as Student E when observing how a Romanian roommate learned Spanish in a matter of "months", and Student F said that in watching television in English one could go from not understanding anything to comprehending everything, "suddenly". In these comments, students focused more on the suddenness of being able to use a language, rather than on the actual process of change and their role within it as a learner.

\section{Individual themes: Incremental descriptors}

Learning progression as step-by-step. Some students focused more on progression in language learning, in particular its slow nature. They may have seen themselves at the higher or lower end of this progression, but they returned multiple times to their personal evolutions in language learning (this may be due to the fact that half of the students were studying English at the time of the interview. Students B, C, and
E discussed how listening was becoming easier for them, and both mentioned what they could not do "yet" in English. Student E commented that she used to feel that English was an insurmountable barrier that caused her a great deal of performance anxiety, but now saw it as an attainable goal because she could do and understand things that she could not before. Student D also felt her views about English acquisition had changed because of her progress. Students B and E even talked about English as a lifelong learning process, and Student $\mathrm{C}$ alluded positively to the idea of being in to learn English for the long haul.

Multiple intelligences and individualized learning. Central to progression for some students was individualized learning and multiple intelligences. They discussed learning as a matter of approach or learning style, which was especially interesting in Student D's discussion of aptitude, in particular because she had been in an instructor position herself. Student B noted how she and her partner learned differently, but she did not compare herself to him in a negative way. She simply said that what he found motivating, she did not. Student C discussed at length his particular distaste for traditional education and that this caused him to search out ways to be engaged so he could learn. Student E talked about this in her anecdote on foreign friends living in Spain and how relative their learning experiences were to their individual situations and attitudes.

Natural learning. Another facet of the concept of incremental learning that was interesting in term of how it was described was a description of "natural" learning. Student C discussed how one learns through the conditions in which one finds oneself, or places oneself, and seemed to see traditional classroom education as a twisting of a natural inclination to learn due to its artificial, performance-orientated obligations. Student D did something similar when she discussed the dearth of productive, active exercises and activities in public school language classes as counter to "natural" learning. Student B also talked about "natural" learning when she discussed how her children have learned English over the years in school programs where English is increasingly important, so that, years down the road, some things just "sound" right to them. Interestingly, in all of these cases, "natural" is not a static or innate definition, but a way to represent human response to the most normally occurring conditions in learning: progressively understanding, assimilating, and responding to one's environment. Though not stated directed, Student E alluded to this idea when she mentioned, multiple times, that necessity pushes one to learn in a new environment.

Active language concepts. Finally, in terms of language concepts, while some students offered more fixed responses, discussing language acquisition in passive terms: about communication as being information received, foundations ("base") in language created or broken, having a language "in the bag," or turning on a language "switch", others had more 
incremental visions. Student E talked at length about "posos," or residue, the mental imprints that begin to form when one learns language, which she compared to learning steps. Student B often used the verb "ampliar" (widen; extend) to talk about the widening of her language knowledge through her efforts, and also mentioned quite a few times the need to aprovecharse or "take advantage" of opportunities to learn English. She also used the term "natural" several times to talk about how language learning was a result of continuous progress. Student $\mathrm{C}$ also talked about language as a naturally occurring process born of social necessity where his ear was slowly getting accustomed to hearing English and his comprehension moved up in percentage points. Student D continually and emphatically discussed the process of learning language as one that developed in tandem with learning styles and interests. In all these cases, language was not simply had. It was quite active and happening, with the learner center stage.

\section{DISCUSSION}

In these students' responses to narrative interviews some interesting patterns emerged which were pertinent to fixed and incremental beliefs associated with language learning and aptitude, in terms of what students emphasized or brought up and how they described it. All mentioned students affirmed having some sort of difficulty with language learning and students talked about it being easier to learn when young and mentioned age. These concepts may be quite ingrained and automatic, as seemed to be the case with the use of the term "to have an ear" for language, which the majority used and which in most cases seems to be an innate, static concept.

In terms of students' belief in the existence of aptitude, which was most interesting to us in this study, all of the interviewed students thought that language aptitude existed (one called it "predisposition" and none felt that he or she had it. This corroborates BALLI studies mentioned earlier, where most students indicate language aptitude exists but few feel they have it.

When offering more detail on just what this habilidad was, the interviewed students in this study gave different definitions. Most students made comments on abilities that others with language aptitude exhibited, like being able to process sounds more quickly, or more thoroughly, being able to switch between languages in a way they could not, or "picking up" and recalling vocabulary easily. In general, interviewed students seemed to understand the term "language aptitude" used here, habilidad, as something above and beyond normal ability. In their comments it was minimally (incremental) something that allowed some to learn languages more easily, and at the other extreme (fixed), something innate that only some people have, which allowed them to learn effortlessly, suddenly, or without error.
In this sense, there was a difference in language aptitude definition in the interviews. In terms of the content, or the what of students' discussion, students listed memory or being able to produce sounds as important to aptitude, and others included more incremental concepts, like being willing to engage in conversations, having an open mind, or having a positive attitude or motivation. This is important detail that we were able to get because of the research instrument, semi-structured, narrative interviews. Some students offering more incremental definitions associated aptitude with a balance of strengths and weaknesses or multiple intelligences in their interview comments. This was in line with Dweck and others' findings in goal orientation studies, where students with more incremental mindsets were more task-orientated when defining language learning goals and less focused on performance (Dweck, 2000). Importantly, the students who made these comments went on to discuss themselves as very present in the working center of the language learning process. The other side of this coin was also clearly visible in the narratives when students focused more on performing in an academic sense, in particular on their failures to perform as (teachers or parents) expected and how much better others were at languages than themselves, such as Student A noted. Here students' comments discussed a hierarchy of language learning components as more or less important, focusing on error correction, spelling, correct pronunciation, listening or having "an ear", the need to have native teachers. Their narratives often discussed these components as attempts at learning that had been discarded, leading up to a more or less proper way to learn. These were also more fixed concepts, and point toward such performance orientations.

The second area we examined was the how of students' descriptions, the linguistic forms students used and the way language was more actively or passively talked about in the interviews. For some students, it often seemed quite entity-like as it was described as a thing: it was had or lost, broken, a switch that gets turned on, a sudden change, a skill in one's toolbag, a series of memorized vocabulary words, or something to be acquired in a few months. In this sense, language acquisition was a fixed concept, a thing one had or lost. This was also related to performance or taskorientations in Dweck's research. Students who understood language simply as a thing to acquire, like a trophy on a shelf, are less likely to see the task strategies needed to reach such a goal and move actively toward these. Dweck noted that performance-orientated students are more likely to abandon active strategizing more quickly and tend to actually avoid challenges (2000).

Where students mentioned language learning components or strategies, for example, there was a perceived "better" way to do things, a way that "works" versus others that do not and only one sort of language success. This corroborates Barcelos (2000) finding where ESL students in the USA believed there was an 
"ideal" way to learn, each with a different interpretation of what that was. Students' emphasis, which again was available due to the use of qualitative data tools, the narrative interview, shows some of these strategies or perceptions of language learning components as a fixed conceptual framework and further solidification of the language-as-entity concept. On the other hand, other students saw language learning as more incremental, as a process that left a residue, posos which aid future study or as something that is "expanded" ("ampliado") or taken advantage of. Most importantly, some students seemed more focused on change and personal progress and less fixated on difficulties and obstacles, indicating the active strategizing Dweck (2000).

These descriptions are indirectly related to agency, and may reflect the degree to which students feel in control of the language learning process, which is one of the key results Dweck (2000) mentioned in her research, that incrementally-minded students felt more free-willed in the learning process while fixed-minded students tend to feel more deterministic and limited. This was again important in the one-to-one interviews where additional data which could not be included in the scope of this paper showed that locus of control was very central to some students' learning descriptions. Many of these students' comments focused on extrinsic forces that influenced their language learning (pushy parents, bad teachers), and less on their own role in the process.

\section{CONCLUSIONS}

An important conclusion drawn from this study was how using narrative interviews as a methodological tool for examining student beliefs was integral to understanding students' perceptions, which emphasizes the importance of study triangulation in investigating student beliefs. The rich language students used to describe their experiences with language learning (language as " residue", as a "foundation" , as something "in the bag," etc.) revealed both the importance of qualitative data as well as the necessity of examining student beliefs at an individual level. In terms of the latter, some of the clearest data arising from this study seemed to come from students who in class showed the most anxious responses to the course in general, in particular Student A, who was one of the most affected by stress in the class, and who revealed important belief barriers, anxiety, and negative self-talk in the interview which all pointed to a fixed perception of language acquisition, all in line with Dweck's findings for fixed mindsets (2000). The narrative that unfolded (perceptions of traumatic experiences with English learning, feeling forced to learn English) explained many of her difficulties in class. On the other hand, another student who mostly focused on her language learning progress and her role in it, describing language aptitude as being "lanzada" "bold" and willing to engage in conversations, was the student who seemed most motivated to learn, who did extra work in and outside of class to progress.
Open-ended, narrative interviews revealed that language students used to describe these beliefs, which speaks volumes about other important concepts, such as cultural myths having "an ear" and learner metaphors. Qualitative tools in this sense shed light on why and how students develop such beliefs, as they tell more about their personal histories with language study, and are vital to gaining more insight onto the details of student beliefs.

\section{Further studies}

Language aptitude definitions in general merit further investigation. Student responses in the interviews were often contradictory, where they usually indicated that anyone could learn a language yet referred to innate abilities that were clearly not available to everyone. In particular it would be interesting to further inquire into the various metaphors that are associated with these special abilities, the "ear" for language, being "bold," "having a foundation", in cultural comparisons. Additionally, an in-depth analysis is due that looks into the interactive nature of these interviews of the sort Choo (2014) calls for when taking narrative interviews as social practice.

\section{REFERENCES}

Anderson, C. \& Kirpatrick, S. (2016). Narrative interviewing. International Journal of Clinical Pharmacy, 38(3), 631-4.

Barcelos, A. M. F., \& Kalaja, P. (2011). Introduction to beliefs about SLA revisited. System, 39(3), 281289.

Barcelos, A.M. (2000). Understanding teachers' and students' language learning beliefs in experience: A Deweyan approach. Unpublished dissertation. The University of Alabama.

Brown, A. (2009). Students' and teachers' perceptions of effective foreign language teaching: a comparison of ideals. The Modern Language Journal, 93,(1) 46-60.

Choo, Y. (2014). Critiquing research interviews from a CA perspective: Treating interview as social practice. ARECLS, 11, 35-54.

Comas-Forgas, R. Francesca, Oliver-Trobat, Miquel F. \& Bauzà-Sampol, AM. (2015). VET students drop-out: Academic performance and motivation as predictive factors. ICERI 2015 Proceedings, 1751.

Cui, Y. (2014). Unpublished dissertation. Beliefs about Language Learning: A Study of Post-Secondary Non-Native Learners of Chinese and Teachers of Chinese in North America. University of Victoria.

Dweck, C. S. (2000). Self-theories: Their role in motivation, personality and development. Philadelphia, PA: Taylor \& Francis.

European Commission. "Work-based learning in Europe: Practices and policies," June, 2013. Retrieved from: http://ec.europa.eu/dgs/education_culture/repositor 
y/education/policy/vocationalpolicy/doc/alliance/work-based-learning-ineurope_en.pdf.

Fielden Burns, L. \& Rico García, M. (2017). Comparative Language Learning Beliefs: Why Aptitude Matters. Studies in Linguistics and Literature (1)2, 129-141. DOI: dx.doi.org/10.22158/s1l.v1n2p129.

Foddy, W. (1993). Constructing questions for interviews and questionnaires. Cambridge: Cambridge University Press.

Fontana, A. (2007). Interview: From Formal to Postmodern. Walnut Creek, CA: Left Coast Press

Gillham, B. (2005). Research reviewing: The range of techniques. New York City: McGraw-Hill.

Horwitz, E. K. (1999). Cultural and situational influences on foreign language learners' beliefs about language learning: A review of BALLI studies. System, 27, 557-576.

Hyvärinen, M. (2007). Analyzing narratives and storytelling. In The Sage Handbook of Social Research Methods. Eds. Alasuutari, P, Leonard Bickman \& Julia Brannen, 447-460.

Miller, G. \& Dingwall, R. (1997). Context and method in qualitative research. Sage Publications.

Minayo M. (2012). Análise qualitativa: teoria, passos e fidedignidade. Ciência \& Saúde Coletive, 17(3), 621-626.

Ministerio de Educación, Cultura y Deporte. "Enseñanzas no universitarias. Formación
Profesional. Curso 2013-2014”, January 29, 2016. Retrieved from:

http://www.mecd.gob.es/servicios-al-ciudadano$\mathrm{mecd} / \mathrm{estadisticas/educacion/no-}$ universitaria/alumnado/Formacionprofesional/2013-2014.html

Mulder, R., Kahmann, K., Laubenbacher, S., \& Messmann, G. (2006). Characteristics of learning environments in secondary vocational education and the relation with work identity. In EARLI SIG Professional Learning and Development Conference, October (pp. 11-13).

Muylaert, C., Sarrubi, V., Gallo, P., Neto, M. \& Reis, A. (2014). Narrative interviews: An important resource in qualitative research. La Revista $d a$ Escola de Enfermagem da USP, 48(2), 184-189.

Nikitina,L. \& Furuoka, F. (2006). Re-examining Horwitz's Beliefs About Language Learning Inventory (BALLI) in the Malaysian Context. Electronic Journal of Foreign Language Teaching, 3(2), 209-219.

ReferNet Spain. Early School Leaving in Spain. July 23, 2013. Retrieved from: http://www.sepe.es/LegislativaWeb/verFichero.do ?fichero=09017edb801510a0.

Szőcs, K. (2017). Teachers' and learners' beliefs about language learning autonomy and its implications in the classroom: A mixed method study. Apples: Journal of Applied Language Studies, 11(2), 125145. 